\title{
Potential of CXCR4/CXCL12 Chemokine Axis in Cancer Drug Delivery
}

\author{
Yan Wang ${ }^{1} \cdot$ Ying Xie $^{1} \cdot$ David Oupický ${ }^{1,2}$
}

Published online: 4 January 2016

(C) Springer International Publishing AG 2016

\begin{abstract}
This review discusses the potential of CXCR4 chemokine receptor in the design of anticancer and antimetastatic drug delivery systems. The role of CXCR 4 in cancer progression and metastasis is discussed in the context of the development of several types of drug delivery strategies. Overview of drug delivery systems targeted to cancers that overexpress CXCR4 is provided, together with the main types of CXCR4-binding ligands used in targeting applications. Drug delivery applications that take advantage of CXCR4 inhibition to achieve enhanced anticancer and antimetastatic activity of combination treatments are also discussed.
\end{abstract}

Keywords CXCR $4 \cdot$ Nanoparticles $\cdot$ Drug delivery $\cdot$ Gene delivery $\cdot$ siRNA delivery $\cdot$ Cancer $\cdot$ Metastasis

\section{Introduction}

Chemokines are signaling proteins secreted by various stromal and epithelial cells capable of inducing concentration gradient-driven chemotactic migration of cells through interaction with their respective chemokine receptors [1]. Based on the number and spacing of N-terminal cysteines, chemokine receptors are divided into four groups $(\mathrm{CXC}, \mathrm{CX} 3 \mathrm{C}, \mathrm{CC}$, and

This article is part of the Topical Collection on Drug Delivery

David Oupický

david.oupicky@unmc.edu

1 Center for Drug Delivery and Nanomedicine, Department of Pharmaceutical Sciences, University of Nebraska Medical Center, Omaha, NE, USA

2 Department of Pharmaceutical Sciences, China Pharmaceutical University, Nanjing, China
CX) [2]. There are 19 different chemokine receptors that all belong to the seven-transmembrane G-protein-coupled receptor family. In tumors, a complex network of chemokines and chemokine receptors controls cell trafficking into and out of the tumor microenvironment and thus mediate crucial parts of the metastatic spread of tumor cells [3]. The corresponding chemokines expressed at the site of metastasis provide chemo-attractive signaling that guides trafficking of tumor cells to distant organ sites. Even though cells from different types of cancer may have different expression profiles of chemokine receptors, CXC receptor 4 (CXCR4) is the most widely expressed chemokine receptor in human cancers, which makes it among the most promising target within the chemokine network for cancer therapy.

\section{CXCR4/CXCL12 Signaling}

CXCL12 binding to CXCR4 initiates multiple downstream signaling pathways and results in various responses, such as increasing intracellular calcium flux, gene transcription, chemotaxis, cell survival, and proliferation [4]. The heterotrimeric $\mathrm{G}$ protein is activated and dissociated into GTP-bound $\alpha$ and $\beta \gamma$ subunits [5]. G $\beta \gamma$ subunits activate two major enzymes, phospholipase C- $\beta$ (PLC- $\beta$ ) and a phosphatidylinositol-3-OH kinase (PI3K). Phosphatidylinositol $(4,5)$-bisphosphate is cleaved by PLC- $\beta$ into two secondary messengers, inositol $(1,4,5)$-trisphosphate (IP3) and diacylglycerol (DAG). IP3 causes the release of $\mathrm{Ca}^{2+}$ from intracellular stores, and DAG activates protein kinase $\mathrm{C}$ and mitogen-activated protein kinase (MAPK) in conjunction with $\mathrm{Ca}^{2+}$, thus contributing to cell migration [6]. $\mathrm{G} \alpha$ or G $\beta \gamma$ subunits activate PI3K leading to tyrosine phosphorylation of components of focal adhesions, including the related adhesion focal tyrosine kinase (RAFTK), the adaptor molecule p130 Cas, and the cytoskeletal protein paxillin, thus 
contributing to reorganization of the actin cytoskeleton and changes necessary for cell migration [7]. Transcription and gene expression are regulated by $\mathrm{G} \alpha \mathrm{i}$ signaling through the PI3K-AKT-NF-KB, MEK1/2, and ERK1/2 axes [8]. The activated AKT can regulate the survival of cells. Dimerization of CXCR4 leads to G protein independent signaling via JAK/ STAT pathway, which promotes cell morphology changes and chemotactic responses [9].

\section{The Role of CXCR4 in Cancer and Cancer Metastasis}

CXCR4 overexpression has been reported in more than 20 human tumor types, including mammary, ovarian, prostate, esophageal, pancreatic, melanoma, and renal cell carcinoma [10]. The upregulation of CXCR4 is associated with changes in multiple growth factors, transcription factors, and hypoxiainducible factors [11-13]. Many preclinical and clinical studies observed significant correlation between CXCR4 expression and metastasis and found that CXCR4 expression is associated with poor survival and aggressive type of cancers. CXCR4 overexpression has been identified as a poor prognostic biomarker. For instance, a microarray study of 2000 invasive breast carcinomas and 214 pre-invasive breast samples revealed the critical role of CXCR4 in cancer progression [14]. Elevated levels of CXCR4 in primary tumors were associated with a higher risk of developing bone metastasis [15]. Another clinical study showed that CXCR4 promotes metastasis through the lymphatic system [16]. Elevated levels of CXCR4 in cancer cells have also correlated with increasing risk of cancer recurrence [17].

By activating intracellular signaling pathways, such as PI3K, MAPK, and Erk1/2, CXCR4 plays a critical role in cancer cell survival, proliferation, invasion, and migration [18-21]. The influence of CXCR4-induced activation of focal adhesion complexes and matrix metalloproteinases mediates degradation of extracellular matrix and contributes to invasion of cancer cells. CXCL12 expression levels are elevated in the brain, bone marrow, lungs, and liver. The CXCL12 concentration gradients then drive movement of CXCR4-positive tumor cells in circulation and are responsible for the process of extravasation and organ-specific metastasis [22].

CXCR4/CXCL12 axis is an important emerging target for developing novel delivery strategies for improved cancer therapies [23,24]. In addition to utilizing CXCR4 overexpression as a simple target for improved ligand-mediated delivery of drugs to tumors, blocking CXCR4/CXCL12 interaction using CXCR4 antagonists or silencing CXCR4 expression by siRNA has potential to prevent primary tumor growth and reduce metastasis, especially when combined with chemotherapy and radiotherapy. This review focuses on the role of CXCR4 in cancer metastasis and its potential in drug delivery systems for cancer therapy. Multiple targeting ligands and CXCR4 antagonists have been developed, including peptides, antibodies, and small organic molecules. The main uses of CXCR4 in drug delivery for cancer therapy are summarized in Scheme 1, and representative examples that explore CXCR4 in drug delivery are summarized in Table 1.

\section{CXCR4 as Target for Ligand-Mediated Delivery and Imaging}

Multiple reports explored the use of CXCR4-binding ligands as a way of improving drug delivery to CXCR4overexpressing tumors. The most popular ligands are based on short CXCR4-binding peptides, but small organic molecules and antibodies have also been explored and are discussed in this section.

\section{CXCR4-Binding Peptides}

Peptide ligands that bind CXCR4 has been widely used to direct drug delivery systems to CXCR4 overexpressing tumor cells with the goal of improving intracellular delivery of antitumor agents by receptor-medicated cellular uptake. Among the most successful has been a peptide T22 derived from horseshoe crab polyphemusin II. The T22 peptide binds CXCR4 and efficiently penetrates target cells via a rapid receptor-specific endosomal route. When conjugated to nanoparticles, T22 mediates delivery and accumulation of the nanoparticles in the perinuclear region of the target cells both in cell culture and in metastatic cancer models in vivo. The T22 peptide has been used for intracellular delivery of proteins, nanoparticles, and imaging agents [25]. Torre et al. have described a CXCR4-targeted delivery system using mesoporous silica nanoparticles that were loaded with doxorubicin and capped with an azide-containing modified T22 peptide by a click reaction [29]. Residues $\mathrm{Tyr}^{5}$, $\mathrm{Lys}^{7}$, and $\mathrm{Tyr}^{12}$ dramatically enhanced the affinity of the T22 peptide for the CXCR4 receptor overexpressed in B-cell non-Hodgkin's lymphoma cells. The peptide capped the pores in the porous nanoparticles to block the release of doxorubicin and facilitated uptake via the CXCR4 receptor. In lysosomes, proteolytic enzymes degraded the T22 peptide and allowed intracellular doxorubicin release.

Wang et al. have investigated a low molecular weight CXCR4 peptide antagonist LFC131 (Tyr-Arg-Arg-Nal-Gly). The authors conjugated the LFC131 peptide to Ocarboxymethyl chitosan nanoparticles and poly(lactide-coglycolide) (PLGA) nanoparticles for enhanced targeted delivery of docetaxel and doxorubicin to CXCR4 overexpressing lung cancer cells [26,27].

To enhance the targeting and killing of tumor cells, Snyder et al. linked another CXCR4 ligand, DV3, to two transducible anticancer peptides: a p53-activating 
CXCR4 Ligands:

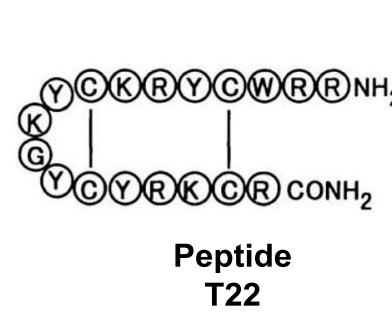

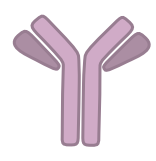

Antibody $12 \mathrm{G5}$
CXCR4 SIRNA:

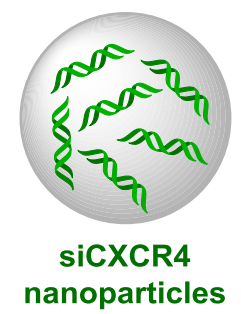

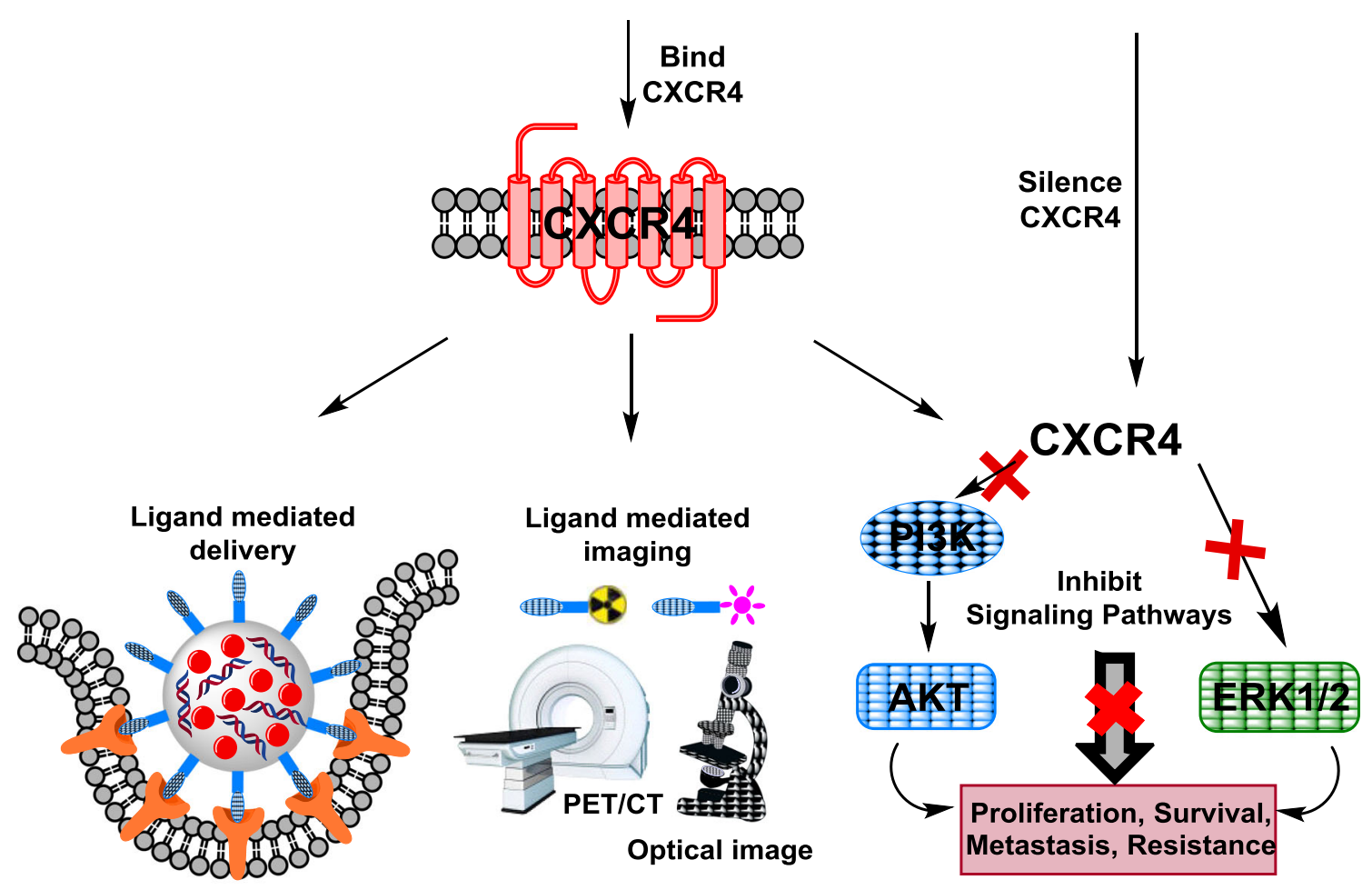

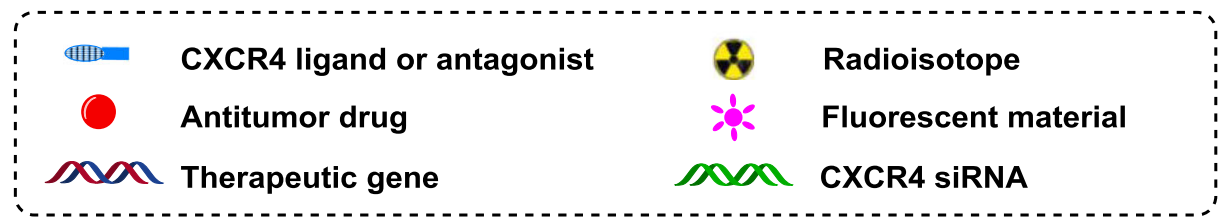

Scheme 1 Summary of the main approaches utilizing CXCR4 in cancer drug delivery

peptide (DV3-TATp53C') and a cyclin-dependent kinase 2 antagonist peptide (DV3-TAT-RxL). Treatment with either of the targeted peptides resulted in an enhancement of tumor cell killing compared with treatment with nontargeted parent peptides [28].

CXCR4-binding peptides have also been successfully used to improve nucleic acid delivery with cationic peptides and cationic polymers. Egorova et al. have developed chemokinederived peptides as carriers for gene delivery [23]. The authors used three synthetic peptides for CXCR4 receptor targeting: two derived from N-terminal sequence of CXCL12 and one from viral macrophage inflammatory protein (vMIP)-II. One of the peptides (KPVSLSYRSPSRFFESH-K9-biotin) derived from CXCL12, consisting of an N-terminal sequence of
CXCL12 (KPVSLSYR) and an RFFESH motif (residues 12-17), was able to specifically target cells overexpressing CXCR4 and to exhibit high transfection efficacy. In a follow-up study, the authors found that the use of the oligolysine (K9) as the DNA-binding moiety compromised the gene delivery due to instability in physiological conditions and lack of endosomolytic properties. To circumvent these problems, the authors developed a gene delivery system using CXCL12-derived cross-linking peptides and demonstrated that a modular peptide KPVSLSYRSPSRFFESH-Ahx-AhxCHRRRRRRHC could be used as efficient gene delivery carrier. The flanking cysteines formed intermolecular disulfide bonds to stabilize the particles and tightly condense DNA. Subsequent internalization and intracellular disulfide 
Table 1 Examples of CXCR4-targeted drug delivery systems

\begin{tabular}{|c|c|c|c|c|}
\hline Targeting moiety & Delivery system & Delivered cargo & Application & References \\
\hline T22 peptide & $\begin{array}{l}\text { Fused fluorescent protein } \\
\text { nanoparticle }\end{array}$ & Green fluorescent protein & $\begin{array}{l}\text { Increase nanoparticle delivery to colorectal } \\
\text { cancer (in vivo) }\end{array}$ & {$[25]$} \\
\hline LFC131 peptide & $\begin{array}{l}\text { Chitosan and PLGA } \\
\text { nanoparticles }\end{array}$ & Docetaxel and doxorubicin & $\begin{array}{l}\text { Increase anticancer drug delivery in lung cancer } \\
\text { (in vitro) }\end{array}$ & {$[26,27]$} \\
\hline DV3 peptide & $\begin{array}{l}\text { Cationic peptide transduction } \\
\text { domain (PTD) }\end{array}$ & Anticancer peptides & $\begin{array}{l}\text { Increase targeting and killing of CXCR4- } \\
\text { positive lymphoma cells }\end{array}$ & [28] \\
\hline $\begin{array}{l}\text { Azide-containing T22 } \\
\text { analog peptide }\end{array}$ & $\begin{array}{l}\text { Mesoporous silica } \\
\text { nanoparticles }\end{array}$ & Doxorubicin & $\begin{array}{l}\text { Increase anticancer drug delivery in lymphoma } \\
\text { cells (in vitro) }\end{array}$ & [29] \\
\hline $\begin{array}{l}\text { N-terminal sequence of } \\
\text { CXCL12 }\end{array}$ & Polyplexes & Reporter plasmid DNA & $\begin{array}{l}\text { Increase gene delivery to CXCR-positive human } \\
\text { glioblastoma and cervical carcinoma cells }\end{array}$ & {$[23,30]$} \\
\hline $\begin{array}{l}\text { Peptide analog 4F- } \\
\text { benzoyl-TE14011 }\end{array}$ & Lipoplexes & Reporter plasmid DNA & Increase gene delivery to rat glioma cells & [31] \\
\hline Ac-TZ14011 peptide & Radiopharmaceutical & ${ }^{111}$ In & $\begin{array}{l}\text { Image CXCR4 expression in metastatic } \\
\text { pancreatic tumors in vivo }\end{array}$ & [32] \\
\hline Ac-TZ14011 peptide & Dendrimers & ${ }^{111}$ In and Cy5.5 dye & $\begin{array}{l}\text { Image CXCR } 4 \text { expression in breast cancer } \\
\text { in vivo }\end{array}$ & {$[33,34]$} \\
\hline X4-2-6 peptide & $\begin{array}{l}\text { Self-assembled peptide } \\
\text { nanoparticles }\end{array}$ & Anticancer drug HKH-40A & Inhibit breast tumor metastasis in vivo & {$[35]$} \\
\hline Anti-CXCR4 antibody & Liposomes & Doxorubicin & $\begin{array}{l}\text { Increase delivery and efficacy of anticancer drug } \\
\text { in breast cancer (in vitro) }\end{array}$ & {$[36]$} \\
\hline Anti-CXCR4 antibody & Liposomes & Anti-lipocalin-2 siRNA & $\begin{array}{l}\text { Inhibit both the CXCR4- and Lcn2-mediated } \\
\text { migratory pathways in metastatic breast } \\
\text { cancer (in vitro) }\end{array}$ & [24] \\
\hline Anti-CXCR4 antibody & Radiopharmaceutical & ${ }^{111}$ In & Image brain tumor by SPECT/CT (in vivo) & [37] \\
\hline AMD3100 & Lipoplexes and polyplexes & Reporter plasmid DNA & $\begin{array}{l}\text { Increase gene transfection in CXCR4-positive } \\
\text { human lymphoma Jurkat cells }\end{array}$ & {$[38]$} \\
\hline AMD3100 & PLGA nanoparticles & siRNA (anti-GFP) & $\begin{array}{l}\text { Increase uptake, suppress CXCR4 signaling and } \\
\text { deliver siRNA in triple negative breast cancer } \\
\text { and metastatic breast cancer (in vitro) }\end{array}$ & [39] \\
\hline AMD3100 & PLGA nanoparticles & Sorafenib & $\begin{array}{l}\text { Target malignant hepatocellular carcinoma and } \\
\text { improve anticancer effect with sorafenib } \\
\text { (in vivo) }\end{array}$ & [40] \\
\hline AMD3100 & Polyplexes & siRNA (siPLK1) & $\begin{array}{l}\text { Simultaneously deliver gene and block CXCR4 } \\
\text { to inhibit metastasis (in vivo, in vitro) }\end{array}$ & [41-44] \\
\hline AMD3100 derivatives & Polyplexes & Reporter plasmid DNA & $\begin{array}{l}\text { Simultaneously deliver gene and block CXCR4 } \\
\text { to inhibit cell invasion (in vitro) }\end{array}$ & {$[45]$} \\
\hline Viologen dendrimers & Dendrimer polyplexes & $\mathrm{TNF} \alpha$ plasmid DNA & $\begin{array}{l}\text { Simultaneously prevent CXCR4-mediated } \\
\text { cancer cell invasion and facilitate TNF } \alpha \text { - } \\
\text { mediated cancer cell killing (in vitro) }\end{array}$ & {$[46]$} \\
\hline AMD3100 & Radiopharmaceutical & ${ }^{64} \mathrm{Cu}$ & $\begin{array}{l}\text { Image lung metastasis derived from human } \\
\text { breast cancer by PET (in vivo) }\end{array}$ & {$[47]$} \\
\hline AMD3465 & Radiopharmaceutical & ${ }^{64} \mathrm{Cu}$ & $\begin{array}{l}\text { Image brain tumor and colon tumor by } \mathrm{PET} / \mathrm{CT} \\
\text { (in vivo) }\end{array}$ & [48] \\
\hline
\end{tabular}

breakage resulted in enhanced gene expression when compared with the K9-based peptides, in part also because of the buffering capacity and membrane activity of the peptide containing histidine and arginine residues [30].

Feasibility of CXCR4 targeting using lipoplexes containing peptide analog 4F-benzoyl-TE14011 was also demonstrated [31]. The peptide ligand (4-fluorobenzoylRR-Nal-CY-Cit-KEPYR-Cit-CR) binds CXCR4 with high affinity $\left(\mathrm{K}_{\mathrm{d}} 1.5 \mathrm{nM}\right)$ and when covalently linked to a phospholipid used in lipoplex formulation resulted in CXCR4-targeted gene delivery.

\section{CXCR4-Binding Small Molecule Organic Ligands}

Synthetic small molecule organic molecules that bind CXCR4 have been among the most successful CXCR4 antagonists. In fact, the only currently FDA-approved CXCR4 antagonist is a cyclam derivative AMD3100 (Plerixafor). AMD3100 has been shown to bind and block CXCR4 signaling in multiple animal models as well as in clinical trials [49, 50]. Several reports exist on the use of drug and gene delivery systems conjugated with small molecule ligands like AMD3100. Probably the first report described a nonviral carrier in which 
AMD3100 was covalently attached to polyethylenimine (PEI) and cationic lipids [38]. The study showed that the CXCR4targeted polyplexes could effectively deliver genes into CXCR4-positive Jurkat cells. The role of CXCR4 in the uptake of the polyplexes was clearly demonstrated when nonspecific internalization pathways were minimized or when phorbolmyristate acetate (PMA) was used to enhance CXCR4 receptor endocytosis. AMD3100 has also been successfully used to target multicompartment PLGA nanoparticles to CXCR4-overexpressing breast cancer cells [39]. In this case, AMD3100 was conjugated to the surface of the nanoparticles by using PLGA with terminal acrylate groups that were reacted with AMD3100 amines via the Michael addition. The targeted nanoparticles were then selectively taken up by CXCR4-overexpressing breast cancer cells, and they also effectively blocked CXCR4 signaling. When loaded with siRNA, the AMD3100-PLGA nanoparticles allowed for more effective gene silencing in vitro than their corresponding nontargeted nanoparticles.

\section{Anti-CXCR4 Antibodies}

Multiple anti-CXCR4 antibodies have been developed and applied as experimental treatments in animal models of cancer metastasis [51,52]. Such antibodies can be also used as ligands to facilitate improved delivery of drug carriers, similar to the peptide and small molecule ligands discussed above $[24,36]$. For example, liposomes targeted with anti-CXCR4 antibody were used to improve doxorubicin activity in CXCR4overexpressing breast cancer cells [36]. The liposomes were prepared by the extrusion using 1,2-dioleoyl-sn-glycero-3phosphoethanolamine-N-dodecanoyl (N-dod-PE) and 1,2dioleoyl-sn-glycero-3-phosphocholine (DOPC), followed by conjugation of mouse anti-human CXCR4 monoclonal antibody via N-dod-PE anchor by EDC/NHS chemistry. Overexpression of CXCR4 was observed in HCC1500 and MDAMB-175VII breast cancer cells relative to normal control cells MCF10As. Expression levels of CXCR4 in the breast cancer cells directly correlated with increased liposome binding and enhanced drug activity. Based on this study, the knowledge of the levels of CXCR4 expression may be used to predict the efficacy of CXCR4-targeted drug delivery systems.

\section{Imaging Agents That Target CXCR4}

Due to the established role of CXCR4 in cancer metastasis, there is a growing interest and potential in using CXCR4binding ligands for imaging of primary and metastatic tumors. CXCR4-binding imaging agents have been developed based on peptide and small molecule organic ligands. For example, using systematic structure-activity relationship study, Hanaoka et al. have developed a radiopharmaceutical for the imaging of CXCR4-expressing tumors in vivo based on the
T22 peptide [32]. The authors designed a peptidic CXCR4 ligand named Ac-TZ14011 (Ac-RR-Nal-CY-Cit-RKPYRCit-CR). The ligand contains four residues $\left(\mathrm{Arg}^{2}, \mathrm{Nal}^{3}, \mathrm{Tyr}^{5}\right.$, and $\mathrm{Arg}^{14}$ ) that formed the intrinsic pharmacophore and were necessary for the CXCR4 inhibition. ${ }^{111}$ In was then used as radionuclide for radiolabeling of the peptide containing diethylenetriaminepentaacetic acid (DTPA) attached to the side chain of D-Lys ${ }^{8}$. The resulting ${ }^{111}$ In-DTPA-Ac-TZ14011 inhibited the binding of CXCL12 to CXCR4 in a concentration-dependent manner with an IC50 of $7.9 \mathrm{nM}$. Biodistribution studies in athymic nude mice bearing subcutaneous CXCR4-overexpressing pancreatic carcinoma cells showed preferential accumulation of ${ }^{111}$ In-DTPA-AcTZ14011 in the tumor. Similarly, Kuil et al. have developed peptide-conjugated dendrimers using Ac-TZ14011 peptide to obtain constructs capable of multimodal imaging. The constructs consisted of a Cy5.5-like fluorophore and a DTPA chelating group for ${ }^{111} \mathrm{In}$ labeling and were used to image CXCR4 expression in breast cancer animal model using both SPECT/CT and fluorescence imaging [33,34].

The cyclam-based CXCR4 antagonists like AMD3100 constitute a diverse class of compounds with the common ability to chelate transition metals in the cyclam macrocycle. These compounds have been used in multiple studies to chelate PET-positive radioisotope ${ }^{64} \mathrm{Cu}$ for imaging of CXCR4expressing tumors. For example, Nimmagadda et al. have reported the development and evaluation of $\left[{ }^{64} \mathrm{Cu}\right]$-AMD3100 to image lung metastasis derived from human MDA-MB-231 breast cancer by PET [47]. Another cyclam-containing CXCR4 ligand, AMD3465, was also used for imaging CXCR4 expression. De Silva et al. reported that $\left[{ }^{64} \mathrm{Cu}\right]-$ AMD3465 was capable of detecting tumor lesions using dynamic and whole-body PET/CT in a CXCR4-dependent fashion with high target selectivity in both U87 brain tumor and HT-29 colon tumor animal models [48].

Anti-CXCR4 antibodies are commonly used for fluorescence microscopy imaging, but they also showed potential in SPECT/CT imaging in vivo. Using ${ }^{125}$ I-labeled antiCXCR4 monoclonal antibody (12G5), the results of a recent study showed successful SPECT/CT imaging of CXCR4positive U87 brain tumors [37]. Compared with isotype control, the tumor-to-tissue uptake ratio for ${ }^{125} \mathrm{I}-12 \mathrm{G} 5$ was 2.5 fold higher at $48 \mathrm{~h}$ after injection, indicating the feasibility of antibody-targeted tumor imaging.

\section{Inhibition of CXCR4 in Anticancer Therapies}

Due to its significant role in multiple steps involved in cancer progression, inhibition of CXCR4 has been explored in various drug delivery systems with the goal of reducing cancer cell proliferation and metastasis. Several strategies have been employed to either directly silence expression of CXCR 4 gene 
in malignant cells using siRNA or to codeliver small-molecule CXCR4 antagonists with other antitumor therapeutics to achieve enhanced anticancer effect.

\section{Silencing of CXCR4 Gene}

Specific targeting and silencing of CXCR4 expression with siRNAs has been proposed to slow down cancer cell growth and metastasis both in vitro and in vivo. CXCR4 expression was significantly downregulated in liver metastasis of colorectal cancer when anti-CXCR4 siRNA was delivered by nanoparticles based on spermine-modified dextran [53,54]. In the study, spermine was conjugated to oxidized dextran by reductive amination process to obtain cationic dextran, and the results showed that CXCR4 silencing decreased the extent of cancer cell and lymphocyte infiltration in the liver of treated animals. In a study of the effect of CXCR4 silencing on metastasis of breast cancer, a fusion protein based on HER2-scFv and arginine nonamer peptide (e23sFv-9R) was developed and tested as siRNA carrier [55]. Delivery of antiCXCR4 siRNA by the e23sFv-9R carrier resulted in decreased CXCR4 expression and subsequent reduction in proliferation and metastasis in HER2-positive breast cancer BT474 cell line in vitro. Importantly, systemic delivery of the anti-CXCR4 siRNA by the fusion protein was able to suppress tumor growth, reduce metastasis, and prolong survival in mice-bearing HER2-positive xenografts.

Tumor progression is associated with intratumoral hypoxia and an abnormal vascular architecture, which provides heterogeneous perfusion within the tumor tissue [56]. Hypoxia regulates the expression of multiple genes involved in angiogenesis, epithelial-mesenchymal transition, extracellular matrix degradation, and chemotaxis [57]. CXCR4 is a potential target in the events associated with hypoxia because of its hypoxiatriggered upregulation. Romain et al. have demonstrated that hypoxia-upregulated CXCR4 expression in colon cancer cells and that CXCR4 expression remained elevated for up to $48 \mathrm{~h}$ even when the cancer cells were returned to normoxic conditions [58]. As a result of the CXCR4 upregulation, the migration of the colon cancer SW480 cells increased up to sixfold in hypoxia when compared with normoxic conditions. Importantly, the increased invasiveness of the cancer cells could be reduced significantly by CXCR4 gene silencing.

\section{Inhibition of CXCR4 in Cancer Metastasis}

In addition to offering a simple targeting to CXCR4overexpressing cancer cells, many of the existing CXCR4binding ligands also function as receptor antagonists and thus inhibit CXCR4/CXCL12 signaling. The inhibition of the CXCR4 signaling can be utilized to achieve additional antitumor and antimetastatic benefits, especially when combined with other simultaneously delivered drugs. There have been a growing number of successful examples of drug and gene delivery vectors that combine delivery function with a pharmacological CXCR4-inhibiting activity, and they will be discussed in this section.

Multiple innovative drug delivery systems that combine CXCR4 inhibition and drug delivery have been reported in recent years. Taking advantage of the structural plasticity of transmembrane peptides, biologically active nanoparticles that effectively inhibit tumor metastasis in vivo have been developed based on a 24-amino acid peptide X4-2-6 which corresponds to the second transmembrane helix of the CXCR4. The peptide self-assembled into nanoparticles that inhibited CXCR4 function in vitro and prevented CXCR4dependent tumor metastasis in MDA-MB-231 breast cancer xenograft model [35]. These nanoparticles could additionally encapsulate hydrophobic antitumor drugs, thus providing an effective combination delivery system. The peptides were capable of assembling into a variety of structures including spherical, fibrous, tubular, and discoid shapes [59]. The ability to control the morphology of the assemblies may allow improved delivery of such peptide particles as it was found that stronger intermolecular interactions observed in nanospheres than in fibrils resulted in slower rates of particle disassembly and in improved protection against proteolytic degradation.

As part of our long-term efforts to develop dually functioning polycations for combination drug/gene delivery, we have designed polycations (polymeric AMD3100 (PAMD)) based on the cyclam CXCR4 antagonist AMD3100. The PAMD polymers showed dual functionality as efficient nucleic acid (gene and siRNA) delivery vectors and CXCR4 antagonists that inhibited invasion of cancer cells in vitro and decreased metastasis in several tumor models in vivo [41,42]. Modification of PAMD with PEG was used to improve the in vivo applicability [44]. Modification with cholesterol was used as a way of enhancing siRNA delivery efficacy of PAMD, while preserving the CXCR4-inhibiting activity of the polymers [43]. Although based on an approved drug and easy to synthesize, PAMD synthesis resulted in the formation of highly branched polymers and in a relatively low CXCR4 antagonistic activity when compared with the original AMD3100. Based on the knowledge of the AMD3100 pharmacophore, we developed a second generation of CXCR4-inhibiting polycations based on a series of linear poly(amido amine)s using Michael-type polyaddition of novel monocyclam monomers. The use of monocyclam monomers allowed preparation of polymers with well-defined architecture and the CXCR4binding moieties present in the sidechain of the polymers, which resulted in improved presentation and accessibility for CXCR4 binding, resulting in greatly increased CXCR4 antagonism [45].

In addition to naturally derived peptides and lipids and polymers based on existing small molecule CXCR4 
inhibitors, dendrimers based on viologen (dialkylated 4,4'bipyridinium salts) have been found to exhibit potent antagonistic activity against CXCR4 [60]. Viologen dendrimers (VGD) were also recently used as a promising class of gene delivery vectors when they demonstrated promising synergistic anticancer activity when used to deliver TNF $\alpha$ plasmid DNA [46].

Similar to the other types of CXCR4 inhibitors, antiCXCR4 antibodies have been used both for their drug targeting ability to CXCR4-overexpressing cancers as well as for their ability to block the CXCR4/CXCL12 signaling in antimetastatic approaches. For example, pHresponsive CXCR4-targeted liposomes were prepared to achieve combined inhibition of CXCR4 and siRNA silencing of lipocalin-2 (Lcn2) [24]. The liposomes were composed of a mixture of DOPC, 1,2-dioleoyl-3dimethylammoniumpropane (DODAP) and N-dod-PE and were modified with anti-CXCR4 antibody to target metastatic breast cancer cells and block cell migration. Liposomes incorporating DODAP responded to the acidic endosomal environment by increasing the cationic character, fusing with the endosomal membrane, and delivering siRNA into the cytoplasm. The combined liposomes significantly reduced migration in triple-negative human breast cancer cells ( $88 \%$ for MDA-MB-436 and $92 \%$ for MDA-MB-231) when compared with inhibition of the CXCR4 or Len2 pathways alone.

\section{Inhibition of CXCR4 as a Chemosensitizing Approach}

Drug resistance remains a serious problem in cancer chemotherapy. Anticancer potency can be greatly improved by combining chemotherapy with a chemosensitizing effect of CXCR4 inhibition. For example, a multikinase inhibitor sorafenib is an anti-angiogenic agent used in the treatment of advanced hepatocellular carcinoma (HCC) and its use results in a significant increase in overall patient survival. However, prolonged sorafenib treatment increases tumor hypoxia due to decreased neovasculature, which in turn upregulates the expression of CXCR4. This causes HCC to acquire more invasive phenotype and to rapidly develop resistance to antiangiogenic therapy with sorafenib [61-63]. AMD3100 can sensitize HCC to sorafenib treatment by inhibiting CXCR4 axis-induced cancer cell proliferation and polarization of the tumor-promoting microenvironment [62]. To take advantage of the chemosensitizing ability of AMD3100, Gao et al. encapsulated sorafenib in lipid-coated PLGA nanoparticles. The surface of the nanoparticles was modified with AMD3100 to allow systemic delivery of the sorafenib/ AMD3100 combination into HCC [40]. The results of the study demonstrated that the nanoparticles could efficiently deliver sorafenib and AMD3100 in HCC and that the combined treatment showed improved anti-angiogenic effect and decreased infiltration of tumor-associated macrophages in vivo. The combined nanoparticle treatment significantly inhibited primary HCC growth and distal metastasis and thus increased overall survival in vivo, indicating clinical potential of CXCR4 inhibition in overcoming acquired drug resistance in $\mathrm{HCC}$.

\section{Potential Problems with CXCR4 Inhibitors and Delivery Systems}

As shown above, combining CXCR4 antagonism with conventional therapies provides opportunity to improve antitumor and antimetastatic activity and potentially decrease disease recurrence [64]. However, chronic administration of CXCR4 inhibitors is needed to achieve such therapeutic benefits, which may lead to adverse effects not seen with current acute administration protocols of CXCR4 inhibitors. CXCR4 is expressed mainly in neutrophils, macrophages, and dendritic cells, which distribute into a variety of healthy tissues including the brain, heart, liver, lung, spleen, and kidney [65-67]. Thus, as with other receptor-targeted delivery systems, CXCR4-targeted nanoparticles that deliver cytotoxic drugs may induce toxicity to the healthy tissues. Due to tumor cells overexpressing multiple types of surface receptors, dualligand nanoparticles might have the potential to enhance selectivity of therapeutic nanocarriers in cancers and reduce toxicity in healthy tissues [68-75]. Another concern with CXCR4 antagonists is their effect on cell mobilization. It is not fully understood how patients can tolerate chronic mobilization of peripheral blood cells or hematopoietic stem/progenitor cells after prolonged CXCR4 inhibition. Patients may experience an increase in leukocytes (leukocytosis) or a decrease in platelets circulating in the blood (thrombocytopenia). The size of the spleen may increase after long-term administration of CXCR4 antagonists, which can result in spleen rupture and cause death. For the future development of CXCR4 inhibitors, cell mobilization issues should be addressed. For instance, a novel CXCR4 antagonist MSX-122 blocks chemotaxis and homing of the CXCR4-positive cancer cells to distant organs without disturbing the retention of hematopoietic progenitor cells in the bone marrow [76]. Progenitor cells express high levels of CXCR 4 and are attracted to CXCL12 produced by stromal cells in the bone marrow niches. MSX-122 is a partial inhibitor of CXCR4/CXCL12 functions and interferes with the $\mathrm{G} \alpha$-signaling pathway; however, elevated CXCL12 in bone marrow can block MSX-122 binding to CXCR4. Thus, MSX-122 and delivery systems utilizing it may offer unique therapeutic opportunities in antimetastatic therapies not available with existing CXCR4 antagonists. Moreover, resistance of tumor cells to CXCR4 inhibitors may represent a potential obstacle. Labrosse et al. reported that single amino acid substitutions in CXCR4 contributed to the resistance to 
AMD3100 [77]. Such structural alternations may take place in the process of tumor development and decrease the efficacy of CXCR4 antagonists. Another potential problem that needs to be highlighted concerns selection of CXCR4 antagonists. Comparative studies between peptide T140 and AMD3100 showed that neither of them functions as pure antagonist and that there are differences in their mechanism of action $[78,79]$. AMD3100 displayed a weak partial agonist activity as its binding to CXCR4 receptor that resulted in CXCL12-like downstream signaling. In contrast, T140 exhibited features of an inverse agonist as it decreased autonomous CXCR4 signaling. Given the involvement of CXCR4 activation in providing prosurvival signals in cancer cells, delivery systems based on T140 might be a better option than those based on AMD3100.

\section{Conclusion}

In this review article, we provide a summary of the role of CXCR4 in cancer metastasis and present evidence to support CXCR4 as an emerging target in designing drug delivery systems aimed at developing novel antimetastatic treatments. The potential of CXCR4 targeted drug delivery systems is supported by a growing number of preclinical studies in a broad range of metastatic cancers and in combination with multiple types of other therapeutics, including small molecule anticancer agents, siRNA, and genes. Further ability to take advantage of the pharmacologic effect of CXCR4 inhibition in designing combination drug delivery strategies is another unique advantage of targeting this chemokine axis in cancer. However, in order to translate the CXCR4-targeted delivery systems to clinical applications, multiple scientific and technical challenges have to be solved. Chief among them is the need to address potential side effects that may result from off-target effects related to prolonged inhibition of CXCR4 in normal processes and delivery of toxic agents to normal cells that express the CXCR4 receptor. Further understanding of the role of CXCR4 and its interplay with other chemokine receptors, such as CXCR7, will be also important for the success of drug delivery strategies that target CXCR4.

Acknowledgments The authors would like to thank the NIH for the financial support (EB015216, EB020308). Support from the Changjiang Scholar Program for D.O. is also acknowledged.

\section{Compliance with Ethical Standards}

Conflict of Interest On behalf of all authors, the corresponding author states that there is no conflict of interest.

Human and Animal Rights and Informed Consent This article does not contain any studies with human or animal subjects performed by any of the authors.

\section{References}

1. Smith H, Whittall C, Weksler B, Middleton J. Chemokines stimulate bidirectional migration of human mesenchymal stem cells across bone marrow endothelial cells. Stem Cells Dev. 2012;21(3):476-86.

2. Le Y, Zhou Y, Iribarren P, Wang J. Chemokines and chemokine receptors: their manifold roles in homeostasis and disease. Cell Mol Immunol. 2004;1(2):95-104.

3. Balkwill FR. The chemokine system and cancer. J Pathol. 2012;226(2):148-57.

4. Ganju RK, Brubaker SA, Meyer J, Dutt P, Yang Y, Qin S, et al. The alpha-chemokine, stromal cell-derived factor-1alpha, binds to the transmembrane G-protein-coupled CXCR-4 receptor and activates multiple signal transduction pathways. J Biol Chem. 1998;273(36): 23169-75.

5. Goldsmith ZG, Dhanasekaran DN. G protein regulation of MAPK networks. Oncogene. 2007;26(22):3122-42.

6. Bendall LJ, Baraz R, Juarez J, Shen W, Bradstock KF. Defective p38 mitogen-activated protein kinase signaling impairs chemotaxic but not proliferative responses to stromal-derived factor-1alpha in acute lymphoblastic leukemia. Cancer Res. 2005;65(8):3290-8.

7. Wang JF, Park IW, Groopman JE. Stromal cell-derived factor-1alpha stimulates tyrosine phosphorylation of multiple focal adhesion proteins and induces migration of hematopoietic progenitor cells: roles of phosphoinositide-3 kinase and protein kinase C. Blood. 2000;95(8):2505-13.

8. Vlahakis SR, Villasis-Keever A, Gomez T, Vanegas M, Vlahakis N, Paya CV. G protein-coupled chemokine receptors induce both survival and apoptotic signaling pathways. J Immunol. 2002;169(10): 5546-54.

9. Mellado M, Vila-Coro AJ, Martinez C, Rodriguez-Frade JM. Receptor dimerization: a key step in chemokine signaling. Cell Mol Biol. 2001;47(4):575-82.

10. Domanska UM, Kruizinga RC, Nagengast WB, Timmer-Bosscha H, Huls G, de Vries EG, et al. A review on CXCR4/CXCL12 axis in oncology: no place to hide. Eur J Cancer. 2013;49(1):219-30.

11. Ishikawa T, Nakashiro K, Klosek SK, Goda H, Hara S, Uchida D, et al. Hypoxia enhances CXCR4 expression by activating HIF-1 in oral squamous cell carcinoma. Oncol Rep. 2009;21(3):707-12.

12. Kubic JD, Lui JW, Little EC, Ludvik AE, Konda S, Salgia R, et al. PAX3 and FOXD3 promote CXCR4 expression in melanoma. J Biol Chem. 2015;290(36):21901-14.

13. Phillips RJ, Mestas J, Gharaee-Kermani M, Burdick MD, Sica A, Belperio JA, et al. Epidermal growth factor and hypoxia-induced expression of CXC chemokine receptor 4 on non-small cell lung cancer cells is regulated by the phosphatidylinositol 3-kinase/ PTEN/AKT/mammalian target of rapamycin signaling pathway and activation of hypoxia inducible factor-1alpha. J Biol Chem. 2005;280(23):22473-81.

14. Salvucci O, Bouchard A, Baccarelli A, Deschenes J, Sauter G, Simon R, et al. The role of CXCR4 receptor expression in breast cancer: a large tissue microarray study. Breast Cancer Res Treat. 2006;97(3):275-83.

15. Andre F, Xia W, Conforti R, Wei Y, Boulet T, Tomasic G, et al. CXCR4 expression in early breast cancer and risk of distant recurrence. Oncologist. 2009;14(12):1182-8.

16. Kato M, Kitayama J, Kazama S, Nagawa H. Expression pattern of $\mathrm{CXC}$ chemokine receptor- 4 is correlated with lymph node metastasis in human invasive ductal carcinoma. Breast Cancer Res. 2003;5(5):R144-50.

17. Chu QD, Holm NT, Madumere P, Johnson LW, Abreo F, Li BDL. Chemokine receptor CXCR4 overexpression predicts recurrence for hormone receptor-positive, node-negative breast cancer patients. Surgery. 2011;149(2):193-9. 
18. Chang L, Karin M. Mammalian MAP kinase signalling cascades. Nature. 2001;410(6824):37-40.

19. Fernandis AZ, Prasad A, Band H, Klosel R, Ganju RK. Regulation of CXCR4-mediated chemotaxis and chemoinvasion of breast cancer cells. Oncogene. 2004;23(1):157-67.

20. Hartmann TN, Burger JA, Glodek A, Fujii N, Burger M. CXCR4 chemokine receptor and integrin signaling co-operate in mediating adhesion and chemoresistance in small cell lung cancer (SCLC) cells. Oncogene. 2005;24(27):4462-71.

21. Luker KE, Luker GD. Functions of CXCL12 and CXCR4 in breast cancer. Cancer Lett. 2006;238(1):30-41.

22. Sun X, Cheng G, Hao M, Zheng J, Zhou X, Zhang J, et al. CXCL12 / CXCR4 / CXCR7 chemokine axis and cancer progression. Cancer Metastasis Rev. 2010;29(4):709-22.

23. Egorova A, Kiselev A, Hakli M, Ruponen M, Baranov V, Urtti A. Chemokine-derived peptides as carriers for gene delivery to CXCR4 expressing cells. J Gene Med. 2009;11(9):772-81.

24. Guo P, You JO, Yang J, Jia D, Moses MA, Auguste DT. Inhibiting metastatic breast cancer cell migration via the synergy of targeted, pH-triggered siRNA delivery and chemokine axis blockade. Mol Pharm. 2014;11(3):755-65.

25. Unzueta U, Cespedes MV, Ferrer-Miralles N, Casanova I, Cedano $\mathrm{J}$, Corchero JL, et al. Intracellular CXCR4(+) cell targeting with T22-empowered protein-only nanoparticles. Int J Nanomedicine. 2012;7:4533-44.

26. Chittasupho C, Lirdprapamongkol K, Kewsuwan P, Sarisuta N. Targeted delivery of doxorubicin to A549 lung cancer cells by CXCR4 antagonist conjugated PLGA nanoparticles. Eur J Pharm Biopharm. 2014;88(2):529-38.

27. Wang RT, Zhi XY, Yao SY, Zhang Y. LFC131 peptide-conjugated polymeric nanoparticles for the effective delivery of docetaxel in CXCR4 overexpressed lung cancer cells. Colloids Surf BBiointerfaces. 2015;133:43-50.

28. Snyder EL, Saenz CC, Denicourt C, Meade BR, Cui XS, Kaplan IM, et al. Enhanced targeting and killing of tumor cells expressing the CXC chemokine receptor 4 by transducible anticancer peptides. Cancer Res. 2005;65(23):10646-50.

29. de la Torre C, Casanova I, Acosta G, Coll C, Moreno MJ, Albericio $\mathrm{F}$, et al. Gated mesoporous silica nanoparticles using a double-role circular peptide for the controlled and target-preferential release of doxorubicin in CXCR4-expressing lymphoma cells. Adv Funct Mater. 2015;25(5):687-95.

30. Egorova A, Bogacheva M, Shubina A, Baranov V, Kiselev A. Development of a receptor-targeted gene delivery system using CXCR4 ligand-conjugated cross-linking peptides. J Gene Med. 2014;16(11-12):336-51.

31. Driessen WH, Fujii N, Tamamura H, Sullivan SM. Development of peptide-targeted lipoplexes to CXCR4-expressing rat glioma cells and rat proliferating endothelial cells. Mol Ther. 2008;16(3):51624.

32. Hanaoka H, Mukai T, Tamamura H, Mori T, Ishino S, Ogawa K, et al. Development of a 111 In-labeled peptide derivative targeting a chemokine receptor, CXCR4, for imaging tumors. Nucl Med Biol. 2006;33(4):489-94.

33. Kuil J, Buckle T, Oldenburg J, Yuan H, Borowsky AD, Josephson L, et al. Hybrid peptide dendrimers for imaging of chemokine receptor 4 (CXCR4) expression. Mol Pharm. 2011;8(6):2444-53.

34. Kuil J, Buckle T, Yuan H, van den Berg NS, Oishi S, Fujii N, et al. Synthesis and evaluation of a bimodal CXCR4 antagonistic peptide. Bioconjug Chem. 2011;22(5):859-64.

35. Tarasov SG, Gaponenko V, Howard OM, Chen Y, Oppenheim JJ, Dyba MA, et al. Structural plasticity of a transmembrane peptide allows self-assembly into biologically active nanoparticles. Proc Natl Acad Sci U S A. 2011;108(24):9798-803.
36. Guo P, You JO, Yang J, Moses MA, Auguste DT. Using breast cancer cell CXCR4 surface expression to predict liposome binding and cytotoxicity. Biomaterials. 2012;33(32):8104-10.

37. Nimmagadda S, Pullambhatla M, Pomper MG. Immunoimaging of CXCR4 expression in brain tumor xenografts using SPECT/CT. J Nucl Med. 2009;50(7):1124-30.

38. Le Bon B, Van Craynest N, Daoudi JM, Di Giorgio C, Domb AJ, Vierling P. AMD3100 conjugates as components of targeted nonviral gene delivery systems: synthesis and in vitro transfection efficiency of CXCR4-expressing cells. Bioconjug Chem. 2004;15(2): 413-23.

39. Misra AC, Luker KE, Durmaz H, Luker GD, Lahann J. CXCR4targeted nanocarriers for triple negative breast cancers. Biomacromolecules. 2015;16(8):2412-7.

40. Gao DY, Lin Ts T, Sung YC, Liu YC, Chiang WH, Chang CC, et al. CXCR4-targeted lipid-coated PLGA nanoparticles deliver sorafenib and overcome acquired drug resistance in liver cancer. Biomaterials. 2015;67:194-203.

41. Li J, Oupicky D. Effect of biodegradability on CXCR4 antagonism, transfection efficacy and antimetastatic activity of polymeric plerixafor. Biomaterials. 2014;35(21):5572-9.

42. Li J, Zhu Y, Hazeldine ST, Li C, Oupicky D. Dual-function CXCR4 antagonist polyplexes to deliver gene therapy and inhibit cancer cell invasion. Angew Chem Int Ed Engl. 2012;51(35):8740-3.

43. Wang Y, Li J, Chen Y, Oupicky D. Balancing polymer hydrophobicity for ligand presentation and siRNA delivery in dual function CXCR4 inhibiting polyplexes. Biomaterials Sci. 2015;3(7):1114 23.

44. Wang Y, Li J, Oupicky D. Polymeric plerixafor: effect of PEGylation on CXCR4 antagonism, cancer cell invasion, and DNA transfection. Pharm Res. 2014;31(12):3538-48.

45. Wang Y, Hazeldine ST, Li J, Oupicky D. Development of functional poly(amido amine) CXCR4 antagonists with the ability to mobilize leukocytes and deliver nucleic acids. Adv Healthcare Mater. 2015;4(5):729-38.

46. Li J, Lepadatu AM, Zhu Y, Ciobanu M, Wang Y, Asaftei SC, et al. Examination of structure-activity relationship of viologen-based dendrimers as CXCR4 antagonists and gene carriers. Bioconjug Chem. 2014;25(5):907-17.

47. Nimmagadda S, Pullambhatla M, Stone K, Green G, Bhujwalla ZM, Pomper MG. Molecular imaging of CXCR4 receptor expression in human cancer xenografts with [64Cu]AMD3100 positron emission tomography. Cancer Res. 2010;70(10):3935-44.

48. De Silva RA, Peyre K, Pullambhatla M, Fox JJ, Pomper MG, Nimmagadda S. Imaging CXCR4 expression in human cancer xenografts: evaluation of monocyclam 64Cu-AMD3465. J Nucl Med. 2011;52(6):986-93.

49. De Clercq E. The bicyclam AMD3100 story. Nature Rev Drug Discov. 2003;2(7):581-7.

50. Smith MC, Luker KE, Garbow JR, Prior JL, Jackson E, PiwnicaWorms D, et al. CXCR4 regulates growth of both primary and metastatic breast cancer. Cancer Res. 2004;64(23):8604-12.

51. Engl T, Relja B, Marian D, Blumenberg C, Muller I, Beecken WD, et al. CXCR4 chemokine receptor mediates prostate tumor cell adhesion through alpha5 and beta3 integrins. Neoplasia. 2006;8(4):290-301.

52. Kuhne MR, Mulvey T, Belanger B, Chen S, Pan C, Chong C, et al. BMS-936564/MDX-1338: a fully human anti-CXCR4 antibody induces apoptosis in vitro and shows antitumor activity in vivo in hematologic malignancies. Clin Cancer Res. 2013;19(2):357-66.

53. Abedini F, Hosseinkhani H, Ismail M, Domb AJ, Omar AR, Chong PP, et al. Cationized dextran nanoparticle-encapsulated CXCR4siRNA enhanced correlation between CXCR4 expression and serum alkaline phosphatase in a mouse model of colorectal cancer. Int J Nanomedicine. 2012;7:4159-68. 
54. Abedini F, Ismail M, Hosseinkhani H, Ibrahim TA, Omar AR, Chong PP, et al. Effects of CXCR4 siRNA/dextran-spermine nanoparticles on CXCR4 expression and serum LDH levels in a mouse model of colorectal cancer metastasis to the liver. Cancer Manag Res. 2011;3:301-9.

55. Jiang K, Li J, Yin JP, Ma Q, Yan B, Zhang X, et al. Targeted delivery of CXCR4-siRNA by scFv for HER2 $(+)$ breast cancer therapy. Biomaterials. 2015;59:77-87.

56. Vaupel P, Kelleher DK, Hockel M. Oxygen status of malignant tumors: pathogenesis of hypoxia and significance for tumor therapy. Semin Oncol. 2001;28(2 Suppl 8):29-35.

57. Harris AL. Hypoxia - a key regulatory factor in tumour growth. Nat Rev Cancer. 2002;2(1):38-47.

58. Romain B, Hachet-Haas M, Rohr S, Brigand C, Galzi JL, Gaub MP, et al. Hypoxia differentially regulated CXCR4 and CXCR7 signaling in colon cancer. Mol Cancer. 2014;13:58.

59. Lee Y, Chen Y, Tarasova NI, Gaponenko V. The structure of monomeric components of self-assembling CXCR4 antagonists determines the architecture of resulting nanostructures. Nanotechnology. 2011;22(50):505101.

60. Asaftei S, Huskens D, Schols D. HIV-1 X4 activities of polycationic "viologen" based dendrimers by interaction with the chemokine receptor CXCR4: study of structure-activity relationship. J Med Chem. 2012;55(23):10405-13.

61. Carmeliet P, Jain RK. Molecular mechanisms and clinical applications of angiogenesis. Nature. 2011;473(7347):298-307.

62. Chen Y, Huang Y, Reiberger T, Duyverman AM, Huang P, Samuel $\mathrm{R}$, et al. Differential effects of sorafenib on liver versus tumor fibrosis mediated by stromal-derived factor $1 \mathrm{alpha} / \mathrm{C}-\mathrm{X}-\mathrm{C}$ receptor type 4 axis and myeloid differentiation antigen-positive myeloid cell infiltration in mice. Hepatology. 2014;59(4):1435-47.

63. Jain RK. Normalizing tumor microenvironment to treat cancer: bench to bedside to biomarkers. J Clin Oncol. 2013;31(17):220518. doi:10.1200/JCO.2012.46.3653.

64. Dubrovska A, Hartung A, Bouchez LC, Walker JR, Reddy VA, Cho $\mathrm{CY}$, et al. CXCR4 activation maintains a stem cell population in tamoxifen-resistant breast cancer cells through AhR signalling. Br J Cancer. 2012;107(1):43-52.

65. Bleul CC, Wu L, Hoxie JA, Springer TA, Mackay CR. The HIV coreceptors CXCR4 and CCR5 are differentially expressed and regulated on human T lymphocytes. Proc Natl Acad Sci U S A. 1997;94(5):1925-30.

66. Federsppiel B, Melhado IG, Duncan AM, Delaney A, Schappert K, Clark-Lewis I, et al. Molecular cloning of the cDNA and chromosomal localization of the gene for a putative seven-transmembrane segment (7-TMS) receptor isolated from human spleen. Genomics. 1993;16(3):707-12.

67. Tashiro K, Tada H, Heilker R, Shirozu M, Nakano T, Honjo T. Signal sequence trap: a cloning strategy for secreted proteins and type I membrane proteins. Science. 1993;261(5121):600-3.

68. Bhattacharyya S, Khan JA, Curran GL, Robertson JD, Bhattacharya R, Mukherjee P. Efficient delivery of gold nanoparticles by dual receptor targeting. Adv Mater. 2011;23(43):5034-8.

69. Chen C, Hu H, Qiao M, Zhao X, Wang Y, Chen K, et al. Anti-tumor activity of paclitaxel through dual-targeting lipoprotein-mimicking nanocarrier. J Drug Target. 2015;23(4):311-22.

70. Meng S, Su B, Li W, Ding Y, Tang L, Zhou W, et al. Enhanced antitumor effect of novel dual-targeted paclitaxel liposomes. Nanotechnology. 2010;21(41):415103-9.

71. Ringhieri P, Diaferia C, Galdiero S, Palumbo R, Morelli G, Accardo A. Liposomal doxorubicin doubly functionalized with CCK8 and R8 peptide sequences for selective intracellular drug delivery. J Pept Sci. 2015;21(5):415-25.

72. Saul JM, Annapragada AV, Bellamkonda RV. A dual-ligand approach for enhancing targeting selectivity of therapeutic nanocarriers. J Control Release. 2006;114(3):277-87.

73. Schubert I, Stein C, Fey GH. Dual-targeting for the elimination of cancer cells with increased selectivity. Antibodies. 2012;1(3):2-18.

74. Sewell SL, Giorgio TD. Synthesis and enzymatic cleavage of dualligand quantum dots. Mater Sci Eng C. 2009;29(4):1428-32.

75. Yang Z, Tang W, Luo X, Zhang X, Zhang C, Li H, et al. Dual-ligand modified polymer-lipid hybrid nanoparticles for docetaxel targeting delivery to Her2/neu overexpressed human breast cancer cells. J Biomed Nanotechnol. 2015;11(8):1401-17.

76. Liang Z, Zhan W, Zhu A, Yoon Y, Lin S, Sasaki M, et al. Development of a unique small molecule modulator of CXCR4. PLoS One. 2012;7(4):e34038.

77. Labrosse B, Brelot A, Heveker N, Sol N, Schols D, De Clercq E, et al. Determinants for sensitivity of human immunodeficiency virus coreceptor CXCR4 to the bicyclam AMD3100. J Virol. 1998;72(8):6381-8.

78. Trent JO, Wang ZX, Murray JL, Shao W, Tamamura H, Fujii N, et al. Lipid bilayer simulations of CXCR4 with inverse agonists and weak partial agonists. J Biol Chem. 2003;278(47):47136-44.

79. Zhang WB, Navenot JM, Haribabu B, Tamamura H, Hiramatu K, Omagari A, et al. A point mutation that confers constitutive activity to CXCR4 reveals that $\mathrm{T} 140$ is an inverse agonist and that AMD3100 and ALX40-4C are weak partial agonists. J Biol Chem. 2002;277(27):24515-21. 